\title{
Tecnologias verdes para um mundo autossustentável: um olhar sobre Brasil e Espanha
}

\author{
Raimundo Nonato Macedo Santos \\ Doutor; Universidade Federal de Pernambuco, Recife, PE, Brasil; \\ rnmacedo@uol.com.br \\ Andrés Pandiella Dominique \\ Doutor; Universidad Carlos III de Madrid, Madrid, Espanha; \\ apandiel@bib.uc3m.es \\ María Luisa Lascurain Sánchez \\ Doutora; Universidad Carlos III de Madrid, Madrid, Espanha; \\ mlascura@bib.uc3m.es \\ Elías Sanz Casado \\ Doutor; Universidad Carlos III de Madrid, Madrid, Espanha; \\ elias@bib.uc3m.es
}

\begin{abstract}
Resumo: O texto discute sobre as tecnologias verdes no âmbito do processo de inovação, com base na análise das patentes verdes solicitadas em nível global e, mais particularmente, no estudo das patentes de prioridade Brasil e Espanha. Patentes verdes aqui entendidas como patentes com foco em tecnologias verdes, ou seja, tecnologias adaptativas e mitigadores das mudanças do clima, o que compreende redução da emissão de carbono e poluição, aumento da eficiência energética e de recursos e a redução da perda de biodiversidade e dos ecossistemas. Do ponto de vista metodológico, formulou-se uma estratégia de busca com base nas tabelas Green Technology Manual Codes. Para a constituição do corpus de 224.673 registros de patentes extraídas da base de dados Derwent World Patents Index - período de cobertura 2004-2013 - o foco foram as tecnologias verdes estabelecidas pela Convenção Marco das Nações Unidas sobre a Mudança Climática. Os resultados do estudo demonstraram a amplitude da mobilização de esforços, ora sob a égide da economia verde, no propósito da mudança do modelo de produção tradicional, não como uma opção, mas como uma tendência imperativa da economia mundial.
\end{abstract}

Palavras-chave: Economia verde. Sustentabilidade. Tecnologias verdes. Inovação. Patentes verdes.

\section{Introdução}

Em âmbito mundial, o crescimento econômico lento e desigual agrava-se ao longo das últimas décadas, com a manutenção do modelo de produção tradicional imputado pela maioria da comunidade científica, como responsável 
pelo esgotamento dos recursos naturais, pela perda de biodiversidade e pelo crescimento dos níveis de contaminação, com consequências irreversíveis.

Em resposta a esse quadro, em junho de 2009, ministros de 34 países assinaram uma Declaração sobre Crescimento Verde, assumindo que iriam: "Intensificar os seus esforços para continuar as estratégias de crescimento verde como parte de suas medidas de enfrentamento da crise e não só, reconhecendo que o verde pode caminhar lado a lado com o crescimento." (ORGANIZAÇÃO PARA A COOPERAÇÃO E DESENVOLVIMENTO ECONÔMICO, 2011).

Com base nessa declaração, a Organização para a Cooperação e Desenvolvimento Econômico (OCDE) propôs a "Estratégia de Crescimento Verde", levando em consideração que nenhum governo contava, de forma autônoma e isolada, com os recursos tecnológicos, científicos, financeiros e de articulação política necessários para pôr em operação uma iniciativa de tamanha envergadura, uma vez que os desafios são globais (ORGANIZAÇÃO PARA A COOPERAÇÃO E DESENVOLVIMENTO ECONÔMICO, 2011).

Para Hargrave e Paulsen (2012), economia verde é uma economia na qual a finitude dos recursos naturais, os serviços e os limites planetários dados pela ciência são levados em consideração e constituem marcos claros, dentro dos quais as atividades de produção, distribuição e consumo poderão ter lugar. Esses autores advogam que, em uma economia verde, os serviços dos ecossistemas são considerados nos processos de tomada de decisão, as externalidades ambientais são internalizadas e questões como mudança do clima, escassez dos recursos naturais, eficiência energética e justiça social são elementos centrais e orientadores do comportamento dos agentes.

Por outro lado, segundo Glass (2012), não há consenso sobre o assunto entre os próprios proponentes da Estratégia de Crescimento Verde, em relação ao que vem a ser economia verde, conforme ficou claro na rodada de negociações de março de 2012.

$\mathrm{Na}$ definição do Programa das Nações Unidas para o Meio Ambiente (Pnuma), "uma economia verde é a que resulta em melhora do bem-estar humano e da equidade social, enquanto reduz significativamente riscos ambientais e a escassez ecológica". Em uma economia verde, se defende que "crescimento em renda e emprego deve ser baseado em investimentos públicos e privados 


\begin{abstract}
que reduzem emissões de carbono e poluição, aumentam a eficiência energética e de recursos e reduzem a perda de serviços da biodiversidade e dos ecossistemas". A economia verde, em suma, "sintetiza o reconhecimento crescente de que alcançar a sustentabilidade depende quase inteiramente em acertar na economia" (UNITED NATIONS ENVIRONMENT PROGRAMME, 2011, p. 16).
\end{abstract}

Apesar da falta de consenso sobre o que caracteriza uma economia verde, a transição do modelo econômico, com base no sistema de produção tradicional para o de uma economia verde, não é uma opção, mas uma tendência da economia mundial (GLASS, 2012). Suportada por novos marcos regulatórios que modificam os preços relativos do uso de recursos (por exemplo, o mercado de carbono) e, também, por mudança de comportamento dos consumidores, como as que se verificam no norte da Europa, a economia verde concretiza-se não só em termos de necessidades de adaptação à novas regulações, mas também em oportunidades de novos negócios.

Apresentando-se, sob essa perspectiva, como uma alternativa a fim de incentivar e promover o crescimento econômico, acompanhado da proteção ambiental que assegure o equilíbrio estável entre o sistema produtivo e o seu entorno, a concepção e a implementação da Estratégia de Crescimento Verde, conforme proposta pela OCDE, busca atingir, de forma simultânea, três desafios: o desenvolvimento e a redução da pobreza, a criação de novas economias baseadas em tecnologias ambientalmente amigáveis, também ditas tecnologias verdes, e a garantia de um mundo cada vez mais verde (HULTMAN et al., 2012).

Sob a condição de protagonista para a imediata e imperativa necessidade de mudança do modelo econômico global, para que as tecnologias verdes possam desempenhar esse papel de destaque que lhes está destinado, é imprescindível que elas estejam suportadas por políticas públicas e incentivos que estimulem e promovam novas formas de criação de valor e de abordagem de problemas compatíveis com ecossistemas saudáveis.

Desse ponto de vista, advoga-se como requisito essencial o fortalecimento da proteção e a consequente ampliação efetiva dos Direitos de Propriedade Intelectual (DPI), como uma prática a fim de incentivar o desenvolvimento e a 
divulgação de tecnologias. A ação multilateral será igualmente necessária para facilitar o acesso dos países menos desenvolvidos às tecnologias verdes (ORGANIZAÇÃO PARA A COOPERAÇÃO E DESENVOLVIMENTO ECONÔMICO, 2003).

Considerando as tecnologias verdes como um dos principais dispositivos para o êxito do processo de implementação da Estratégia de Crescimento Verde, as reflexões sobre elas justificam o trabalho que se propõe a analisar o estágio em que se encontram as políticas de implementação dessa estratégia de criação de novas economias de incentivo e promoção do crescimento econômico global.

Esta investigação apresenta como propósito prospectar tendências de ampliação dos conceitos de inovação não convencionais, de novas relações ciência-tecnologia e sociedade, de novos modelos de aferição do conjunto de atividades inovadoras nas universidades brasileiras e espanholas. Assim, vinculado a esse contexto, o estudo estabeleceu como objetivo caracterizar a inovação sobre tecnologias verdes a partir das análises quali-quantitativas de patentes verdes solicitadas em escala global, e, mais particularmente, do estudo das patentes de prioridade Brasil e Espanha.

Dispositivo jurídico que protege, mediante a comunicação pública da invenção, o privilégio para a exploração comercial daquilo que a invenção descreve, as patentes são os indicadores de produção tecnológica mais utilizados. Ao mesmo tempo, a informação oferecida por meio das patentes facilita a medição da capacidade inventiva de um país, de áreas emergentes de inovação, e permite esclarecer a estrutura produtiva de seus agentes, do momento em que se estabelecem relações entre número de patentes e atividades inventivas (ORGANIZAÇÃO PARA A COOPERAÇÃO E DESENVOLVIMENTO ECONÔMICO, 2009; SANTOS, 1996).

Nesse contexto, as patentes verdes, em alinhamento com as políticas públicas de combate às mudanças climáticas, apresentam-se como um forte incentivo para estimular a inovação verde. Além disso, ao mesmo tempo elas funcionam como um instrumento para potencializar a transferência de conhecimento entre os países mais desenvolvidos e os menos industrializados (COPENHAGEN ECONOMICS, 2009). 
Nessa perspectiva, considera-se de interesse o estudo do papel que exercem as patentes no desenvolvimento e na difusão das tecnologias verdes, por meio das análises das informações que esses registros contêm. O mais importante é que essa iniciativa se coaduna com a investigação que se está desenvolvendo, no âmbito de um programa de pós-doutorado, que se realiza junto ao Observatorio IUNE - Actividad Investigatoria en la Universidad Española, vinculado às Universidades Carlos III de Madri, Autônoma de Madri, Autônoma de Barcelona e Pompeu Fabra, também em Barcelona.

\section{Métodos}

Para a constituição dos corpora dos pedidos de patentes verdes, com foco em tecnologias ambientalmente amigáveis ou ditas tecnologias verdes, estabelecidas pela Convenção Marco das Nações Unidas sobre a Mudança Climática (CMNUCC, de 1994), (EE.UU., 1992) formulou-se uma estratégia de busca com base nas tabelas Green Technology Manual Codes (CLARIVATES ANALYTICS, [2016?]) - códigos do sistema de classificação de patentes propostos pelo Derwent Innovations Index, sistema de informação de patentes da empresa Thomson Reuters Web of Science.

A iniciativa de Derwent Innovations Index em propor a tabela Green Technology Manual Codes como dispositivo para classificar, indexar e, consequentemente, permitir busca e recuperação mais precisa das patentes verdes na base de dados Derwent World Patents Index vem ao encontro da crescente demanda do mercado, verificada por serviços e produtos verdes, junto a empresas que estão investindo pesadamente em pesquisa, no domínio das tecnologias verdes.

A área de cobertura das patentes verdes, indexadas na base de dados Derwent World Patents Index (DWPI), compreende os domínios da Química, das Ciências da Vida e da Engenharia, no que se relacionam a transporte verde (por exemplo, veículos híbridos, elétricos fuel cell e outros meios de transporte com zero emissão), fontes alternativas de energia (energia eólica, solar, 
biodiesel, entre outras) e todas e quaisquer tecnologias que possibilitem o controle de poluição e/ou redução de emissão de carbono.

As buscas das patentes verdes, na base de dados DWPI, foram realizadas durante o mês de maio de 2016. Organizadas as buscas, com base nos códigos da classificação Derwent propostos segundo os grandes temas da tabela Green Technology Manual Codes, fixou-se como período de cobertura mais representativo no contexto deste estudo o intervalo entre 1 de janeiro de 2004 e 31 de dezembro de 2013, portanto, 10 anos. A Tabela 1 apresenta os resultados das buscas, segundo os grandes temas.

Tabela 1 - Quantidade de registros de patentes verdes segundo grandes temas do Green Technology Manual Codes

$\begin{array}{ll}\text { TEMAS } & \text { FREQ } \\ \text { GREEN TRANSPORTATION } & 75296 \\ \text { GREEN POWER SOURCES \& ENERGY } & \\ \text { GENERATION } & 29711 \\ \text { GREEN FUEL } & 10623 \\ \text { ENVIRON AWARENESS } & 11408 \\ \text { POLLUTION CONTROL } & 61606 \\ \text { RECYCLING } & 36029 \\ \text { TOTAL Fonte: Dados da pesquisa. } & 224673\end{array}$

$\mathrm{Na}$ Tabela 1, dois temas destacam-se em relação aos demais, Green Transportation e Pollution Control, representando no corpus objeto do estudo $60,9 \%$ dos registros de patentes verdes recuperados na base de dados DWPI. Além disso, todos os dados dos registros recuperados foram normalizados no software bibliométrico VantagePoint. Para o conjunto das análises realizadas, foram utilizados indicadores unidimensionais e multidimensionais. As representações gráficas foram obtidas a partir do Excel e de aplicativos do VantagePoint.

\section{Resultados}

$\mathrm{Na}$ sequência, são apresentados os resultados das análises das patentes indexadas na base de dados Derwent World Patents Index, sobre a temática do 
estudo, no período de 2004 a 2013, tanto em escala global como das patentes em primeira prioridade do Brasil e da Espanha.

\subsection{Patentes verdes em escala global}

No período de 2004 a 2013, foram indexados, na base de dados Derwent World Patents Index, 224.673 registros de patentes de invenção. Importados esses registros para o VantagePoint, buscou-se, inicialmente, identificar e extrair as duplicatas de registros, utilizando-se como chave de localização dos registros duplicados "cadeias idênticas de caracteres dos títulos das referências", por meio de aplicativo com fim específico, recurso do VantagePoint. Essa operação identificou $12 \%$ de registros duplicados. Extraídos esses registros, o corpus, objeto deste trabalho, reduziu-se a um total de 197.842 registros.

A Tabela 2 apresenta a distribuição temporal de depósito dos registros de patentes verde no período de compreendido entre 2004 e 2013. O destaque desse resultado é para o crescimento expressivo de $47,1 \%$ dos registros de patentes verdes indexados na base de dados DWPI no ano de 2010, quando comparado ao ano de 2009, crescimento esse que continuou de forma bastante significativa nos anos seguintes, 2011-2013. O destaque desse resultado pode ser atribuído, de forma assertiva, como uma repercussão à iniciativa da assinatura da Declaração sobre Crescimento Verde pelos ministros de 34 países, anteriormente mencionados.

Tabela 2 - Distribuição temporal das patentes verdes depositadas na base de dados DWPI 2004 a 2013.

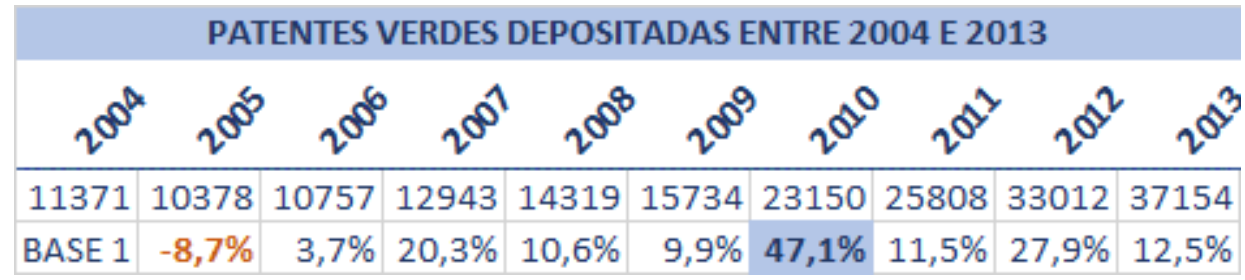

Fonte: Dados da pesquisa.

A Tabela 3 apresenta os resultados das frequências absoluta e relativa dos registros de patentes verdes de prioridade - primeira prioridade, para 
Derwent, prioridade básica -, dos países com mais de 100 registros indexados na base de dados DWPI. China e Japão, somando 56,06\% do total das prioridades das patentes verdes, destacam-se de forma expressiva dos demais países. Computando-se a esse resultado, os registros de patentes de prioridade da República da Coreia, a região da Ásia, detém em torno de $63 \%$ do total desses registros. No entanto, o que chama mais a atenção é o fato de que, entre 45 países com prioridades em patentes verdes contemplados aqui, quase $2 / 3$ das patentes $(74,63 \%)$ encontram-se sob o monopólio de quatro países - China, Japão, Estados Unidos e República da Coreia.

Tabela 3 - Frequências absoluta e relativa de registros de patentes verdes por país indexados na base de dados DWPI - 2004-2013.

\begin{tabular}{|l|l|l|l|l|l|}
\hline PAÍSES & FREQ & $\mathbf{\%}$ & PAÍSES & FREQ & $\%$ \\
\hline CHINA & 58020 & $29,33 \%$ & ESPANHA & 468 & $0,24 \%$ \\
\hline JAPÃO & 52877 & $26,73 \%$ & CANADÁ & 408 & $0,21 \%$ \\
\hline OMPI & 22979 & $11,61 \%$ & AUSTRÁLIA & 261 & $0,13 \%$ \\
\hline ESTADOS UNIDOS & 22579 & $11,41 \%$ & POLÔNIA & 259 & $0,13 \%$ \\
\hline REP. DA COREIA & 14173 & $7,16 \%$ & ITÁLIA & 185 & $0,09 \%$ \\
\hline ALEMANHA & 9951 & $5,03 \%$ & MÉXICO & 161 & $0,08 \%$ \\
\hline OEP & 4400 & $2,22 \%$ & HOLANDA & 142 & $0,07 \%$ \\
\hline FRANÇA & 3040 & $1,54 \%$ & ROMÊNIA & 140 & $0,07 \%$ \\
\hline FED. RUSSA & 2067 & $1,04 \%$ & HUNGRIA & 123 & $0,06 \%$ \\
\hline TAIWAN & 1793 & $0,91 \%$ & ÁUSTRIA & 117 & $0,06 \%$ \\
\hline REINO UNIDO & 1203 & $0,61 \%$ & REP. CHECA & 115 & $0,06 \%$ \\
\hline BRASIL & 881 & $0,45 \%$ & SUÉCIA & 102 & $0,05 \%$ \\
\hline ÍNDIA & 757 & $0,38 \%$ & > DE 100 REG. & 641 & $0,32 \%$ \\
\hline
\end{tabular}

Fonte: Dados da pesquisa.

A base de patentes da Derwent (DWPI) indexa todos os documentos de patente por meio de uma classificação - Derwent Class Codes- considerada, por princípio, muito simples. Junto à base de dados, essa Classificação é aplicada por profissionais de indexação, segundo os temas tratados nos documentos de patente, com o objetivo de possibilitar que seus usuários consigam formular estratégias de pesquisa e realizar buscas de forma segura e precisa, nos temas tecnológicos que lhes dizem respeito. Nesse sentido, em nível geral, a Classificação da DWPI estrutura-se em três grandes domínios: Chemical sections A, B, C, D, E, F, G, H, J, K, L, M; Engineering - sections $\mathrm{P}, \mathrm{Q} ; \mathrm{e}$ Electrical and Electronic - sections S, T, U, V, W, X. 
A análise dos assuntos tratados pelas patentes verdes recuperadas na DWPI, com base nos grandes temas da tabela Green Technology Manual Codes, está representada na Tabela 4. Pelo que se pode observar, nesse recorte, somente dois domínios, entre os três da Classificação como um todo, estão contemplados nos resultados apresentados: Chemical-sections A, D, E, H, J, L; e Electrical and Electronic - sections T, X.

No domínio da Química, por exemplo, entre os anos 2009 e 2010, a indexação de registros de patente verde nas subseções A85 - aplicações de polímeros em componentes elétricos (circuitos, cabos, placas etc.) - e L03 aplicações de materiais refratários e cerâmicos para a fabricação de componentes elétricos, tais como condutores, resistências, ímãs, condensadores interruptores, baterias, acumuladores etc. - mais que dobrou em ambas as subseções: A85 em 159,8\% e L03 em 104,2\%.

A indexação de patentes verdes nas demais subseções da Química, embora não tenha crescido entre 2009 e 2010 na mesma proporção das subseções A85 e L03, cresceu de forma expressiva nos anos seguintes, até 2013. Nesse sentido, cabe destaque para as subseções D15 - tratamento de água, resíduos industriais e de esgotos e D16 - indústria de fermentação, incluindo equipamento de fermentação. Assim, analisando o resultado apresentado na Tabela 4, no domínio da Química, o número de patentes verdes indexadas nas quatro subseções acima mencionadas multiplicou de duas a três vezes entre 2009 e 2013: A85 em 272,5\%; L03 em 207,15; D16 em 139,0\%; e D15 em $98,5 \%$.

No domínio da Elétrica/Eletrônica, a Seção X - Electric Power Engineering - apresenta destaque expressivo em três subseções: X16, X21 e $\mathrm{X} 22$, respectivamente, (Electrochemical Storage) Primary, secondary and fuel cells and batteries; (Electric Vehicles) Electric cars, trolleybuses. Propulsion, braking e; (Automotive Electrics) Vehicle accessories. Vehicle lighting. IC engine ignition. As três juntas indexam cerca de quase $40 \%$, para ser mais preciso 39\%, dos temas indexados sobre patentes verdes, com maior destaque para o tema X21, que participa com $21,2 \%$ da indexação de todas as patentes verdes constantes do corpus analisado. Entre 2009 e 2013, as participações na 
indexação das patentes verdes dessas seções cresceram: X15 - 369,6\%; X16 $207,3 \%$ e X21 - $159,7 \%$.

Tabela 4 - Distribuição temporal das subseções do DerwentClass Codes utilizadas para indexar as patentes verdes recuperadas na DWPI 2004-2013 com frequência acima de 10.000

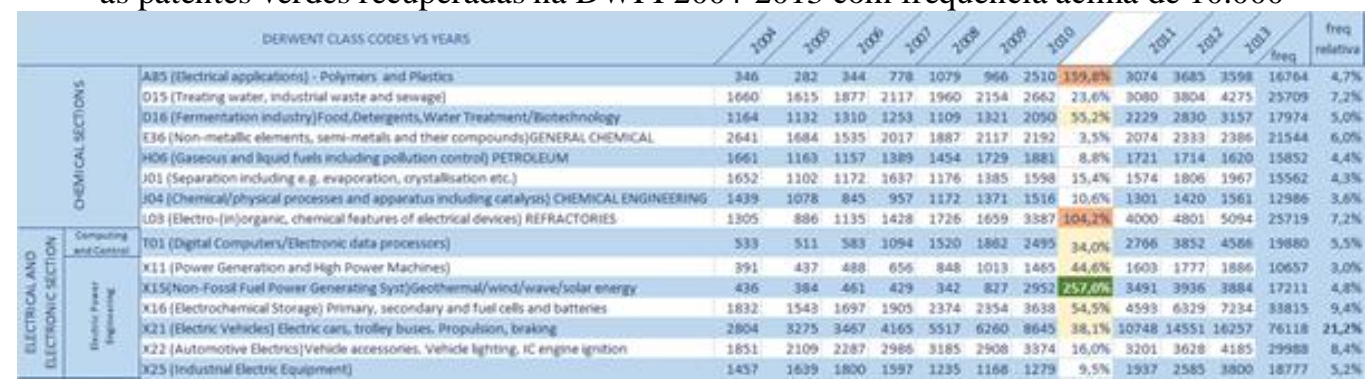

Fonte: Dados da pesquisa.

O Gráfico 1 apresenta o percentual dos códigos - classificação DerwentClass Codes - que os países do corpus analisado utilizaram para indexar as patentes verdes, em primeira prioridade, depositadas. Conforme se apresenta de forma marcante, o código X21 - (Electric Vehicles) Electric cars, trolleybuses. Propulsion, braking - foi, de maneira geral, utilizado de forma exaustiva por todos os países - Alemanha (29\%), Taiwan (27\%), França (24\%), EUA (21\%), China (18\%), Coreia e Reino Unido (17\% cada), Índia e Espanha (16\% cada), Canadá (12\%), Brasil (11\%) e Rússia (8\%). Nesse tema, chama a atenção o fato de o Japão, país com uma indústria automobilística notável, não constar na base de dados Derwent com sequer um registro de patente verde em $\mathrm{X} 21$.

Observando mais em detalhe o Gráfico 1, verifica-se que a Seção X Electric Power Engineering como um todo, X25, X22, X21, X16, X15 e X11 foi utilizada na indexação das patentes verdes de praticamente todos os países. No domínio da Química, por outro lado, cabe destacar primeiro a Seção D16 indústria de fermentação, incluindo equipamento de fermentação -, também indexando patentes em todos os países, com a Índia aparecendo em primeiro lugar, com 17\% dos seus registros indexados nesse domínio. Em segundo, a Seção D15 - tratamento de água, resíduos industriais e de esgotos -, presente nas patentes em todos os países, em que a Rússia é mais representada com 22\% das suas patentes indexadas nessa classe. 
Gráfico 1 - Códigos de cobertura das patentes verdes indexadas nos países segundo classificação DerwentClass Codes

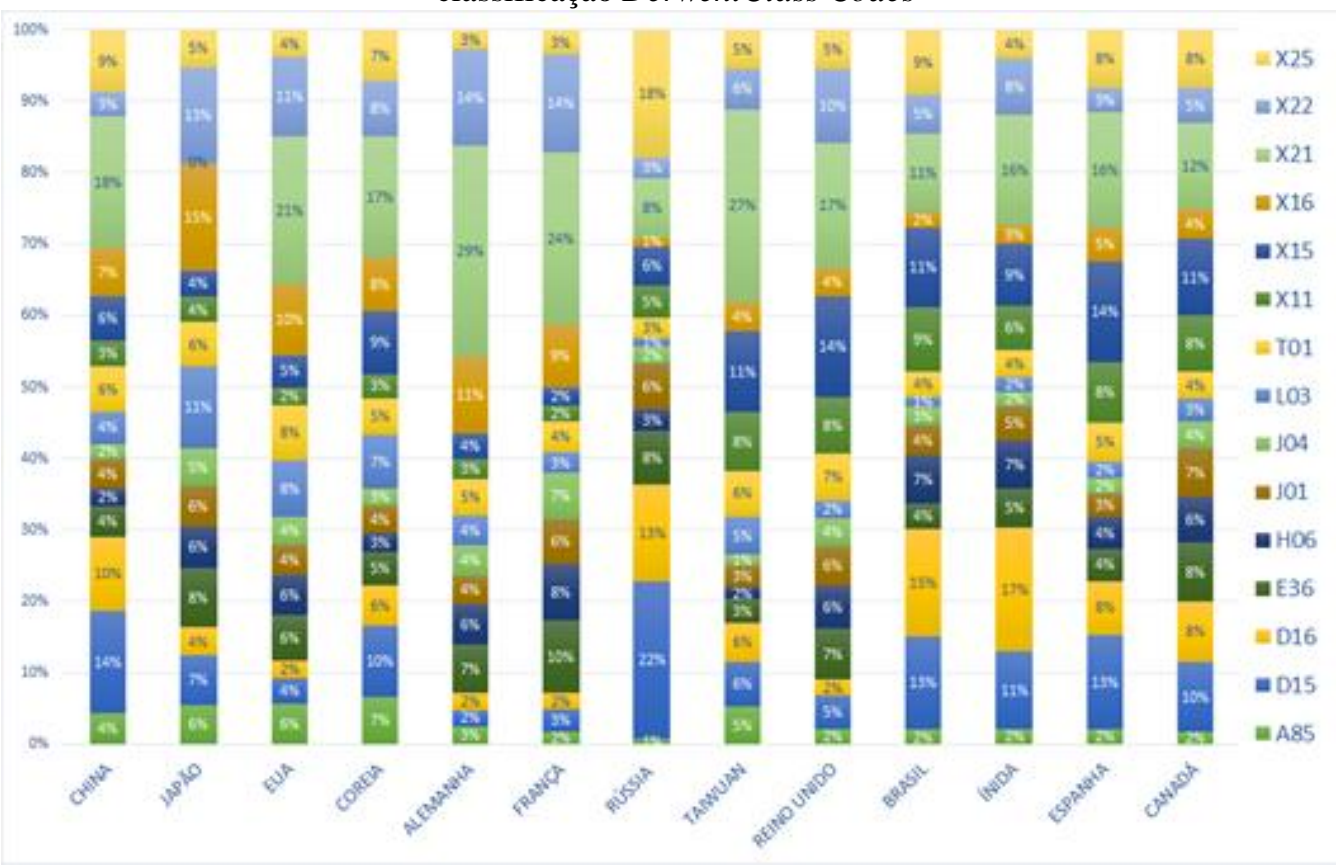

Fonte: Dados da pesquisa.

Os resultados das análises dos depósitos em primeira prioridade das patentes verdes por países até aqui apresentados corroboram a importância da assinatura da Declaração sobre Crescimento Verde de estímulo à promoção, em escala global, da transição do modelo econômico com base no sistema de produção tradicional para o de uma economia verde, evidenciando, como já dito anteriormente, que este modelo não é uma opção, mas uma tendência da economia mundial.

\subsection{Patentes em primeira prioridade - Brasil e Espanha}

Conforme já mencionado, a inclusão da análise dos registros de patentes verdes reivindicadas em primeira prioridade por Brasil (BR) e Espanha (ES) coadunase com a investigação que se está desenvolvendo no âmbito de um programa de pós-doutorado que se realiza junto ao Observatorio IUNE, e, principalmente, justifica-se na inter-relação das circunstâncias que envolvem laços históricos, culturais, humanos e políticos, acordos e programas de apoio à pesquisa 
colaborativa internacional entre Brasil e Espanha, firmados desde o início da década de 1990.

Desse modo, enquanto a Tabela 3 apresenta as frequências dos registros de patentes verdes reivindicadas em primeira prioridade pelo Brasil (BR) com 881 depósitos e pela Espanha (ES) com 468, para o período entre 2004 e 2013, os resultados das análises dos códigos de cobertura das patentes verdes, segundo a classificação DerwentClass apresentados no Gráfico 1, aqui restrito aos dois países, conforma-se no Gráfico 2, no formato radar, apresentado em valores relativos.

Verifica-se que a Espanha, tanto em relação aos temas analisados quanto comparada ao Brasil, concentra maior esforço na Seção X - Electric Power Engineering, subseção X21 (Electric Vehicles) Electric cars, trolleybuses. Propulsion, braking, com 16,3\% contemplado em 84 depósitos de patentes verdes, enquanto o Brasil concentra 11,1\% e contempla 75 depósitos. Na subseção X15 (Non-Fossil Fuel Power Generating Systems) Geothermal, wind, wave, solar energy, types of power generation, com 14,2\%, contemplado com 73 depósitos de patentes verdes e, o Brasil com 11,1\% e 75 depósitos de patentes indexadas nessa subseção.

O Brasil, por outro lado, em comparação com a Espanha, destaca-se na Seção D Food, Detergents, Water Treatment and Biotechnology, particularmente, na subseção D16 - Fermentation industry - including fermentation equipment, em que concentra 14,9\% do seu esforço em relação a todas as demais subseções, contemplando 101 depósitos de patentes verdes indexadas nesse domínio. Em comparação, a Espanha, nesse mesmo domínio, concentra 7,6\%, com 39 depósitos de patente indexados. Já na subseção D15 Treating water, industrial waste and sewage, em termos relativos, Brasil e Espanha concentram os mesmos esforços, 13,2\% em relação às demais subseções, com uma cobertura de 89 registros de patentes verdes em prioridade Brasil e 68 em prioridade Espanha. 
Gráfico 2 - Códigos de cobertura das patentes verdes indexadas com prioridade ES e BR, segundo a classificação DerwentClass Codes, em valores relativos

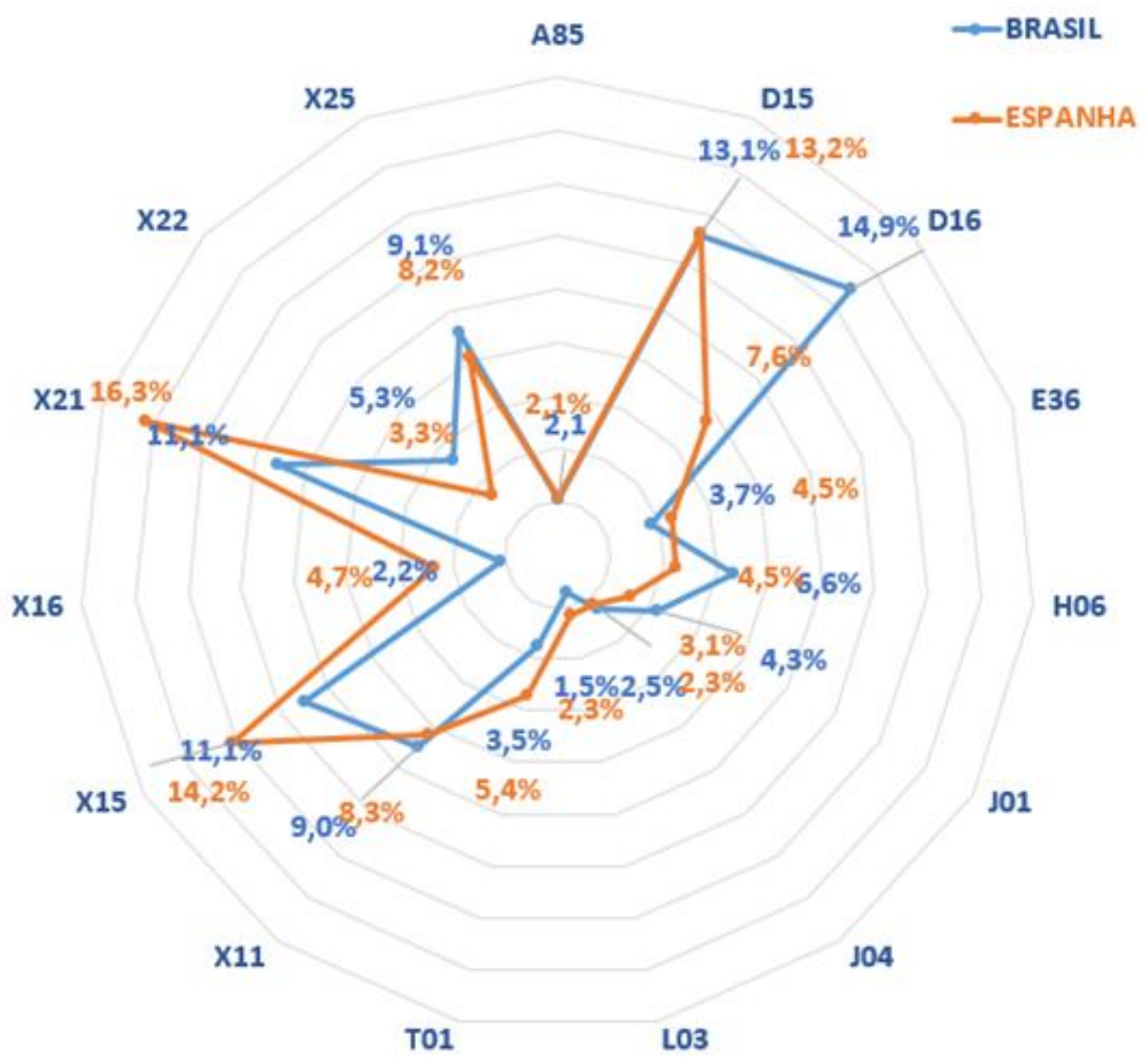

Fonte: Dados da pesquisa.

No Gráfico 3, a linha em cor laranja separa as áreas de especialização, representadas pelos descritores extraídos dos títulos dos registros de patentes verdes dos dois países. Computados em valores relativos, todos os descritores que estão superpostos próximos da linha laranja sinalizam que ambos os países concentraram esforços iguais de produção de conhecimento nos domínios aí representados. Os descritores que se sobressaem em cada um dos lados indicam os domínios de maior competência de um país em relação ao outro. De uma maneira geral, os resultados, apresentados no Gráfico 3, reafirmam os resultados obtidos com os códigos Classificação Derwent, Gráfico 2. Por exemplo, o descritor "WATER" apresenta forte correção com todos os documentos de patentes verdes indexados com D15. O mesmo verifica-se nas correlações com os demais descritores representados no gráfico. 
Gráfico 3 - Determinação das posições relativas dos domínios de competência Espanha e Brasil, representados pelos descritores extraídos dos títulos dos registros de patentes verdes depositadas

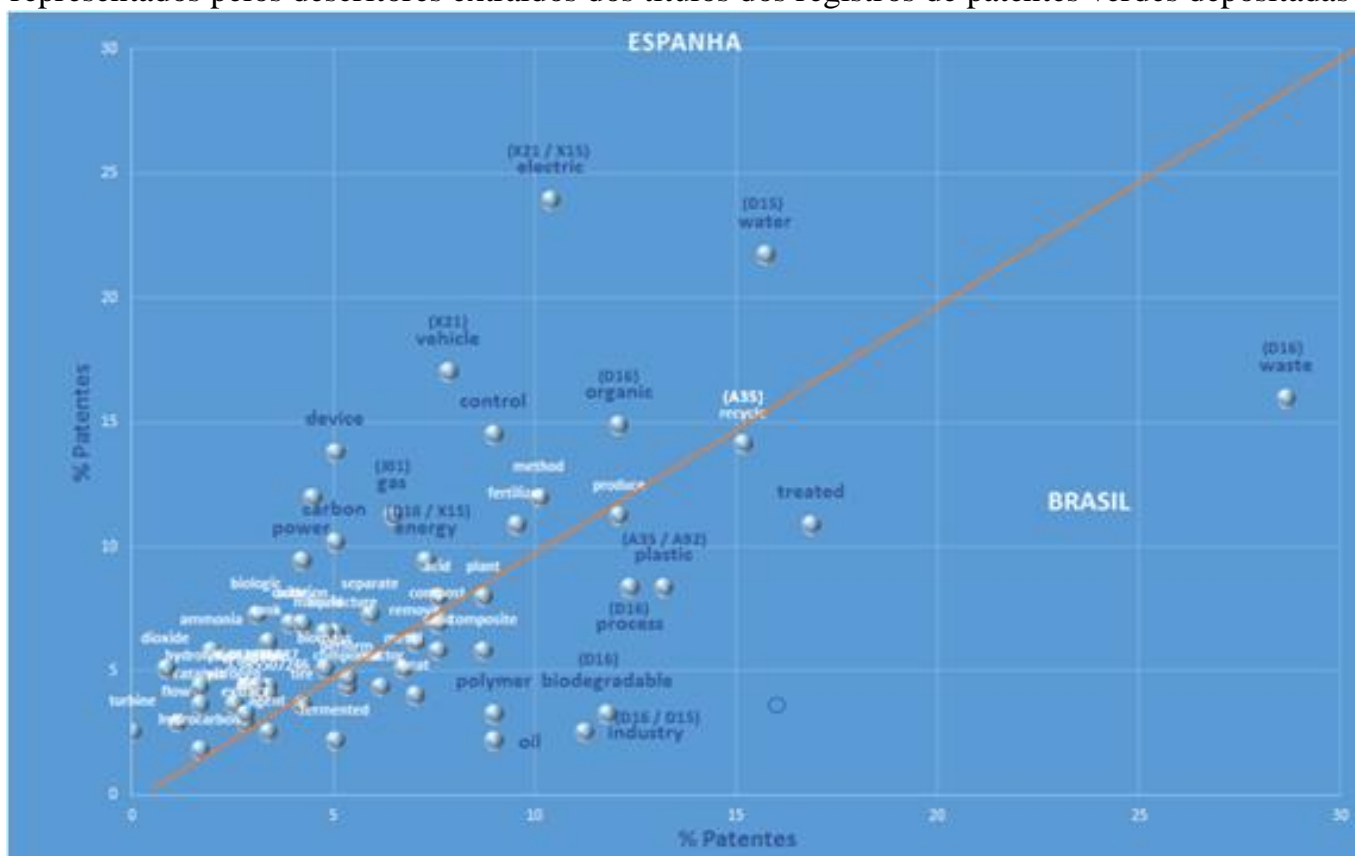

Fonte: Dados da pesquisa.

$\mathrm{Na}$ Tabela 5, analisando-se a distribuição temporal das patentes verdes depositadas em primeira prioridade pela Espanha e pelo Brasil no período de 2004 a 2013, observa-se que os depósitos de patentes com prioridade Espanha, diferentemente das patentes de prioridade Brasil, repercutem de forma significativa a iniciativa da assinatura da Declaração sobre Crescimento Verde. Assim, com exceção do ano 2012, com um crescimento zero em relação a 2011, as patentes com prioridade Espanha continuaram crescentes nos dois outros anos, 2011 e 2013. Já os depósitos das patentes verdes de prioridade Brasil, embora apresentando aumento expressivo no ano 2010 em relação a 2009, de cerca de 60\%, não sustenta esse aumento nos triênio 2011/2013. No ano de 2012, os depósitos de patente verdes no Brasil caíram 32,6\% em relação a 2011.

Tabela 5 - Distribuição temporal das patentes verdes depositadas em primeira prioridade ES e BR na base de dados DWPI - 2004 a 2013

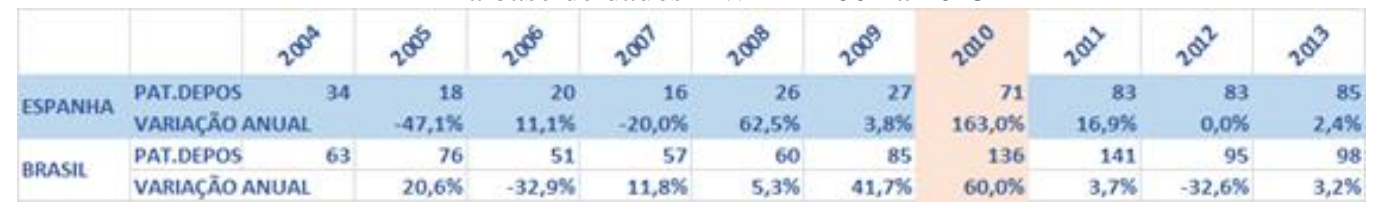

Fonte: Dados da pesquisa. 
A Tabela 6 apresenta a distribuição temporal das patentes verdes de prioridade Espanha e Brasil depositadas somente por entidades públicas e privadas - empresas, universidades, instituições e $P \& D$, incluindo entidades de fomento. Sendo assim, não foram incluídas, nessa análise, as patentes depositadas por indivíduos. Dessa forma, o que fica evidenciado nessa distribuição temporal é que, tanto com relação às patentes de prioridade Espanha como as de prioridade Brasil, são as empresas que repercutem de forma mais positiva a iniciativa da assinatura da Declaração sobre Crescimento Verde.

Tabela 6 - Distribuição temporal das patentes verdes depositadas em primeira prioridade ES e BR, por entidades públicas e privadas, na base de dados DWPI - 2004 a 2013

\begin{tabular}{|c|c|c|c|c|c|c|c|c|c|c|c|c|}
\hline \multirow{5}{*}{ ESPANHA } & DONOS & \multirow{4}{*}{$\begin{array}{l}\text { EMPRESAS } \\
\text { UNIVERSIDADES } \\
\text { INSTS. DEP\&D } \\
\text { CIA }\end{array}$} & 11 & 3 & 11 & 5 & 12 & 7 & 26 & 26 & 31 & \\
\hline & DAS & & 6 & 3 & 1 & 1 & 5 & 6 & 10 & 9 & 12 & 13 \\
\hline & PATENTES & & 1 & 1 & 2 & & 2 & 1 & 8 & 5 & 5 & 4 \\
\hline & FREQUENCIA & & $18^{\prime}$ & $7^{\prime}$ & $14^{\prime}$ & $6^{\prime}$ & $19^{\prime}$ & $14^{\prime}$ & $44^{\prime}$ & $40^{\prime}$ & $48^{\prime}$ & 37 \\
\hline & VARIAÇĀO & ANUAL & & $-61,1 \%$ & $100,0 \%$ & $-57,1 \%$ & $216,7 \%$ & $-26,3 \%$ & $214,3 \%$ & $-9,1 \%$ & $20,0 \%$ & $-22,9 \%$ \\
\hline \multirow{5}{*}{ BRASIL } & \multirow{2}{*}{$\begin{array}{l}\text { DONOS } \\
\text { DAS }\end{array}$} & \multirow{3}{*}{$\begin{array}{l}\text { EMPRESAS } \\
\text { UNIVERSIDADES } \\
\text { INSTS. DE P\&D }\end{array}$} & 7 & 17 & 18 & 11 & 14 & 22 & 23 & 28 & 16 & 24 \\
\hline & & & 6 & 11 & 5 & 5 & 7 & 9 & 15 & 12 & 8 & 8 \\
\hline & PATENTES & & 7 & 5 & 5 & 3 & 3 & 2 & 3 & 4 & 5 & 4 \\
\hline & \multicolumn{2}{|c|}{ FREQUENCIA } & 20 & 33 & 28 & 19 & 24 & 33 & 41 & 44 & 29 & 36 \\
\hline & \multicolumn{2}{|c|}{ VARIAC̄̄OO ANUAL } & & $65,0 \%$ & $-15,2 \%$ & $-32,1 \%$ & $26,3 \%$ & $37,5 \%$ & $24,2 \%$ & $7,3 \%$ & $-34,1 \%$ & $24,1 \%$ \\
\hline
\end{tabular}

Fonte: Dados da pesquisa.

Pelo que se pode constatar, na análise do conjunto de resultados dos depósitos das patentes verdes com prioridade Espanha e Brasil, muito embora constem, entre seus itens de produção de conhecimento, os temas de maior destaque do programa proposto de crescimento verde - Transporte Verde e Controle Ambiental -, do ponto de vista quantitativo, a resposta proporcionada, particularmente, pelo aparato público de Ciência, Tecnologia e Inovação, tanto da Espanha, quanto do Brasil - universidades e instituições públicas de pesquisa -, apresenta-se pouco expressiva, e não reativa.

\section{Conclusão}

De um modo geral, em escala global, os resultados deste estudo demonstraram a amplitude da mobilização de esforços no propósito da mudança do modelo de produção tradicional, imputado como responsável, com consequências irreversíveis, pelo esgotamento dos recursos naturais, pela perda de 
biodiversidade e pelo crescimento dos níveis de contaminação; em síntese, uma ameaça à sobrevivência do homem no planeta. Uma nova agenda, ditada por uma economia verde, não como uma opção, mas como uma tendência imperativa da economia mundial, se conforma.

Da mesma forma, a assinatura da Declaração sobre Crescimento Verde por ministros de 34 países que respalda a proposta da Estratégia do Crescimento Verde, em 2009, de iniciativa da OCDE, demonstra que a formulação e a implementação de políticas públicas, em escala global, que visam à melhoria do bem-estar humano e da equidade social, proporcionam impactos imensuráveis, com retornos positivos e a curto prazo, reduzindo os riscos ambientais e a escassez ecológica.

Em resposta a essa iniciativa, como os resultados mostram, dois importantes retornos podem ser contabilizados. Primeiro, o volume de tecnologias desenvolvidas, especialmente, a partir do ano de 2010. Segundo este ainda de maior importância - configura-se ênfase nos domínios de transporte verde e de controle ambiental.

A confiabilidade e a consistência dos resultados obtidos aqui estão asseguradas pelo volume dos dados que constituiu o corpus deste estudo, cerca de 200 mil registros. Além disso, os resultados são respaldados, também, pela qualidade dos dados extraídos da base de dados DWPI, com base na estratégia de busca formulada conforme a estrutura das tabelas Green Technology Manual Codes, proposta com o fim específico de indexação e recuperação de registro de patentes verdes pela DWPI e pelos recursos de tratamento de corpus disponibilizados por softwares especializados, aplicados com vistas à normalização e à padronização dos registros. Tudo isso associado à exploração de documento tipo patente, dispositivo jurídico que protege, mediante a comunicação pública da invenção, o privilégio para a exploração comercial daquilo que a invenção descreve, indicador de produção científica por excelência.

Por fim, dois aspectos nos resultados obtidos merecem ser objeto de maior atenção. Em âmbito específico, verifica-se a tímida mobilização de esforços em prol da pesquisa e do desenvolvimento de conhecimentos no 
domínio das tecnologias verdes pelo aparato público de Ciência, Tecnologia e Inovação, tanto da Espanha, quanto do Brasil. Em âmbito global, percebe-se, na forma como os resultados apresentam-se, em que $75 \%$ do monopólio do conhecimento está sob domínio de quatro países, isto é, a configuração de um modelo monopolístico de distribuição do conhecimento cada dia mais assimétrico.

\section{Financiamento}

Conselho Nacional de Desenvolvimento Científico e Tecnológico (CNPq Brasil) e Ministerio de Economía y Competitividad (Espanha, CSO2014-51916-C2-1R, "Analysis of the scientific and technological strengths of the ecoeconomy in Spain based on quantitative and qualitative R\&D+I indicators" y CSO20145888-JIN, "Detection of new front of research and innovation in energy efficiency in Spain").

\section{Referências}

CLARIVATES ANALYTICS. Green technology manual codes. [S.1., 2016?]. Disponível em: 〈http://ip.thomsonreuters.com/dwpi_greencodes>. Acesso em: 03 mai. 2016.

COPENHAGEN ECONOMICS. Assessment of barriers to trade and investment between the EU and Japan: report prepared for the European Commission. Copenhagen: DG Trade, 2009.

EE.UU. Convención marco de las naciones sobre el cambio climático. Nueva York: Naciones Unidas, 1992

GLASS, V. O lado B da economia verde. Desafios do Desenvolvimento, Brasília, ano 9, n. 72, 2012.

HARGRAVE, J.; PAULSEN, S. Economia verde e desenvolvimento sustentável. Desafios do Desenvolvimento, Brasília, DF, ano 9, n. 72, 2012.

HULTMAN, N. E. et al. Factors in low-carbon energy transformations: comparing nuclear and bioenergy in Brazil, Sweden, and the U.S. [S.1.] Energy Policy, v. 40 p. 131-146, Jan. 2012.

ORGANIZAÇÃO PARA A COOPERAÇÃO E DESENVOLVIMENTO ECONÔMICO. A caminho do crescimento verde: um sumário para os decisores políticos: maio de 2011. Paris, 2011. 


\title{
ORGANIZAÇÃO PARA A COOPERAÇÃO E DESENVOLVIMENTO
} ECONÔMICO. Manuel de l'OCDE sur les statistiques des brevets. Paris: OECD Publishing, 2009. Disponível em: <http://dx.doi.org/10.1787/9789264056466-fr〉. Acesso em: 2 set. 2016.

\section{ORGANIZAÇÃO PARA A COOPERAÇÃO E DESENVOLVIMENTO}

ECONÔMICO. The impact of trade-related intellectual property rights on trade and foreign direct investment in developing countries, OECD Papers, Paris, v. 3, n. 11, p. 4, Nov. 2003.

SANTOS, R. N. M. Sistemas de informações estratégicas para a vitalidade da empresa. Ciência da Informação, Brasília, v. 25, n. 1, 1996. Disponível em: <http://revista.ibict.br/ciinf/index.php/ciinf/article/view/482>. Acesso em: 2 set. 2016.

UNITED NATIONS ENVIRONMENT PROGRAMME. Towards a green economy: pathways to sustainable development and poverty eradication. [S. 1.]: UNEP, 2011.

\section{Green technologies for a self-sustaining world: a look over Brazil and Spain}

\begin{abstract}
The paper discusses about green technologies in the scope of the innovation process, based on the analysis of the green patents requested in a global level and, more specifically, on the study of the priority patents Brazil and Spain. Green patents, defined here, as patents that have focus in green technology, that is, adaptive and mitigation technologies of the climate change, which comprehends reduction of carbon emissions and pollution, efficient increase of energy and resources and reduction of the biodiversity loss and the ecosystems. From the methodological point of view, a search strategy was formulated based on the Green Technology Manual Codes tables. The established concept of the green technology by the United Nations Framework Convention on Climate Change was used to build the corpus of the 224.673 patent registers extract from Derwent World Patents Index data bases, between 2004 and 2013. The results of the analysis demonstrate the extent of the efforts mobilization, sometimes set up under the aegis of the green economy, which aims to change the traditional production model, not only as an option but as an imperative trend of the world economy.
\end{abstract}

Keywords: Green economy. Sustainability. Green technologies. Innovation. Green patents.

Recebido em: 06/11/2016

Aceito em: 06/01/2017 